\title{
PRODUÇÃO DE MUDAS DE MARACUJAZEIRO CULTIVADA COM DIFERENTES DOSES DE CALCÁRIO DOLOMÍTICO
}

\author{
Silas dos Reis Lima ${ }^{1}$; Halyne Rosa da Silva²; Andréa Hentz de Mello ${ }^{3}$; Genival Reis dos \\ Santos $^{4}$; Fernando Kidelmar Dantas de Oliveira ${ }^{5}$. \\ ${ }^{1}$ Universidade Federal do Pará. Marabá, Pará, Brasil. silas.2007@ hotmail.com \\ ${ }^{2}$ Universidade Federal do Sul e Sudeste do Pará. Marabá, Pará, Brasil. halynerosa_agro@ @otmail.com \\ ${ }^{3}$ Universidade Federal do Sul e Sudeste do Pará. Marabá, Pará, Brasil. andreahentz@ufpa.br \\ ${ }^{4}$ Empresa de Assistência Técnica e Extensão Rural do Estado do Pará. Marabá, Pará, Brasil. \\ ${ }^{5}$ Universidade Federal do Sul e Sudeste do Pará. Marabá, Pará, Brasil. kidelmar@ufpa.br
}

\begin{abstract}
RESUMO: A produção de mudas de qualidade é de extrema importância para o melhor desenvolvimento da cultura do maracujazeiro. $\mathrm{O}$ experimento foi conduzido em condições de casa de vegetação da Universidade Federal do Pará, Campus de Marabá com objetivo de verificar qual a dose de calcário dolomítico promoveria melhor desempenho nas mudas de maracujá-amarelo. Utilizaram-se os seguintes tratamentos: $\mathrm{T}_{1}$ como testemunha utilizando apenas solo; tratamentos $\mathrm{T}_{2}, \mathrm{~T}_{3}, \mathrm{~T}_{4}$ e $\mathrm{T}_{5}$ utilizando $30 \%$ de esterco de aves como substrato com a aplicação de 5, 10, 15 e $20 \mathrm{~g}$ de calcário dolomítico, respectivamente. O delineamento experimental utilizado foi o inteiramente casualizado. Os parâmetros avaliados foram: altura das plantas, diâmetro do caule, número de folhas e avaliação de macro e micronutrientes da parte aérea e radicular das plantas. Verificou-se que os tratamentos com calcário não diferiram estatisticamente entre si, no entanto apresentaram resultados superiores ao tratamento $\mathrm{T}_{1}$. A maior absorção de macronutrientes ocorreu nos tratamentos com calcário, em contrapartida a maior assimilação dos micronutrientes do pelo tratamento $\mathrm{T}_{1}$.
\end{abstract}

PALAVRAS-CHAVE: adubo orgânico, calagem, Passiflora edulis.

\section{SEEDLING PRODUCTION OF PASSION FRUIT GROWN WITH DIFFERENT DOLOMITIC LIMESTONE}

\begin{abstract}
The production of quality seedlings is one of the basic points to a better development of the culture of passion. The experiment was conducted under greenhouse conditions at the Federal University of Pará, Campus Maraba in order to verify the dose of lime promote better performance in seedlings of passion fruit. The following were used: $\mathrm{T}_{1}$ as a control using only ground; treatments $\mathrm{T}_{2}, \mathrm{~T}_{3}, \mathrm{~T}_{4}$ and $\mathrm{T}_{5}$ using $30 \%$ chicken manure as substrate with the application of $5,10,15$, and $20 \mathrm{~g}$ of lime, respectively. The experimental design was completely randomized. The parameters evaluated were: plant height, stem diameter, number of leaves and evaluation of macro and micronutrients in shoots and roots of plants. It was found that the treatments with lime not statistically different, however showed better results than the $\mathrm{T}_{1}$. The greater absorption of nutrients occurred in treatments with lime, in contrast to greater absorption of micronutrients by $\mathrm{T}_{1}$.
\end{abstract}

KEYWORDS: liming, organic fertilizer, Passiflora edulis. 


\section{INTRODUÇÃO}

Atualmente o estado do Pará é um dos mais importantes produtores de maracujá do Brasil, juntamente com Bahia, São Paulo, Minas Gerais e Sergipe, estados nos quais se destaca a importância da cultura no agronegócio brasileiro, na geração de divisas e empregos (AGRIANUAL, 2000).

O maracujazeiro doce (Passiflora alata Curtis) apresenta-se como a segunda espécie em importância econômica no Brasil, sendo os maracujazeiros amarelo (Passiflora edulis fflavicarpa Degener) e roxo (Passiflora edulis Sims) os mais plantados (OLIVEIRA et al., 1994). Cerca de 150 espécies de Passiflora são indígenas do Brasil (HOHNE, 1946), e segundo Pereira et al. (1971) mais de 70 espécies apresentam frutos comestíveis.

Os solos das regiões tropicais apresentam, normalmente, pouca disponibilidade de fósforo às plantas e elevado poder de adsorção/precipitação do nutriente (NOVAIS; SMYTH, 1999). Porém, do ponto de vista nutricional, o nutriente é indispensável para o completo ciclo das plantas, influenciando de modo particular o crescimento de raízes (MARSCHNEV, 1995).

Apesar da maioria dos estudos sobre adubação fosfatada na cultura do maracujazeiro ter sido conduzido durante a fase adulta das plantas, alguns trabalhos têm indicado resposta positiva sobre o desenvolvimento da cultura, na fase de mudas (MACHADO, 1998; PRADO et al., 2004) o que indica a necessidade de mais estudos, para subsidiar recomendações de adubação, visando a obtenção de plantas com bom padrão na fase inicial de desenvolvimento.

Dentre poucos trabalhos com a aplicação de calcário no maracujazeiro na fase de muda, Prado et al. (2004) verificaram que as mudas de maracujazeiro responderam a aplicação de calcário em substrato com reação ácida, observando que o maior desenvolvimento das mudas ocorreu quando esteve associado à saturação por bases do solo de $56 \%$. Por outro lado, existem relatos na literatura mostrando a redução do crescimento vegetativo do maracujazeiro, em função do aumento do nível de saturação por bases (FONSECA, 2002). Assim, observa-se que as indicações da literatura sobre a resposta do maracujazeiro à calagem ainda são contraditórias.

$\mathrm{Na}$ propagação por sementes, o substrato tem a finalidade de proporcionar condições adequadas à germinação e desenvolvimento inicial da muda. Assim, um bom substrato é aquele que proporciona condições adequadas à germinação e ao desenvolvimento do sistema radicular da muda em formação (RAMOS et al., 2002). 
O maracujazeiro extrai grande quantidade de nutrientes, sendo o nitrogênio e o potássio os mais absorvidos pela planta, em torno de 205 $\mathrm{kg}$ de N/ha/ano e $221 \mathrm{~kg}$ de $\mathrm{K}_{2} \mathrm{O} / \mathrm{ha} / \mathrm{ano}$ (HAAG et al., 1973), para uma produtividade de 24,5 t/ha. Segundo São José (1994), pode-se forçar o crescimento das mudas com uma adubação nitrogenada, via irrigação, feita semanalmente com uma solução de 5 a $10 \mathrm{~g}$ de uréia por litro de água, e o solo deverá estar o mais próximo de sua neutralidade.

Souza et al. (2004) afirmam que substratos contendo esterco de curral, casca de café, carvão vegetal, areia e solo com pH próximo de 7 na proporção de 1:1:1:1:2 v/v constitui-se em uma boa alternativa para formação de mudas de maracujá amarelo. Feldberg et al. (2004), também afirmam que substratos contendo Plantmax®, casca de café, pó de serra, areia e solo na proporção 1:1:1:1:2 v/v são substratos que podem proporcionar melhor qualidade na formação de mudas de maracujazeiro amarelo. Além da produtividade do maracujazeiro, as características físicas do fruto e químicas do suco variam, entre outros fatores, com a adubação empregada (MÜLLER et al., 1979).
O uso de substratos de boa qualidade (química e física) permite a produção de mudas mais vigorosas, mesmo quando se utilizam recipientes com menos volume de substrato (ARAÚJO NETO et al., 2002).

Desta forma, a produção de mudas de qualidade é um dos pontos primordiais, para garantir um bom desenvolvimento da cultura do maracujazeiro, sendo importante o emprego de práticas que possam assegurar a formação de mudas vigorosas e resistentes ao plantio no campo (VERDIAL et al., 2000).

Isso pode ocorrer a partir da utilização de técnicas de produção, destacando-se o balanceamento da adubação, além de ser importante a utilização de substrato que cause grande influência sobre a germinação das sementes na formação das mudas (DAVI et al. 2008).

Este trabalho teve como objetivo observar o desempenho de mudas de maracujazeiro submetidas a doses crescentes de calcário dolomítico.

\section{MATERIAL E MÉTODOS}

$\mathrm{O}$ experimento foi conduzido em condições de casa de vegetação da Faculdade de Ciências Agrárias de Marabá, da Universidade Federal do Pará, 
no município de Marabá- Pará, em janeiro de 2012 .

O delineamento experimental utilizado no ensaio foi o inteiramente casualizado, com cinco tratamentos e quatro repetições, totalizando 20 parcelas experimentais, sendo que cada parcela foi constituída de dez sacos para mudas, totalizando 200 mudas.

Os tratamentos constituíram em: $\mathrm{T}_{1}$ como testemunha utilizando apenas solo; tratamentos $\mathrm{T}_{2}, \mathrm{~T}_{3}, \mathrm{~T}_{4}$ e $\mathrm{T}_{5}$ utilizando $30 \%$ de esterco de aves com a aplicação de 5, 10, 15 e 20 g de calcário dolomítico, respectivamente.

O solo utilizado foi classificado como ARGISSOLO VERMELHO-AMARELO Álico (SANTOS et al., 2006).

Os parâmetros avaliados foram: altura da planta $(\mathrm{cm})$, diâmetro de caule $(\mathrm{mm})$, número de folhas e avaliação de macro e micronutrientes da parte aérea e radicular das mudas.

As amostras de esterco, solo e matéria seca das mudas foram encaminhadas para realização de análise no Laboratório de Análise Agronômica e Consultoria Fullin Ltda, no Estado do Espírito Santo.

Os dados coletados foram submetidos à análise de variância, e as médias das características comparadas pelo teste de Tukey, a 5\% de probabilidade, por meio do aplicativo computacional ASSISTAT Versão 7.5 beta (SILVA, 2008).

\section{RESULTADOS E DISCUSSÃO}

ANÁLISES DE CRESCIMENTO VEGETATIVO DAS MUDAS

Verificou-se que para os parâmetros altura das plantas, diâmetro do caule e número de folhas das mudas de maracujá dos tratamentos submetidos à aplicação de calcário dolomítico, não diferiram estatisticamente entre si, no entanto apresentaram valores superiores as mudas do tratamento $\mathrm{T}_{1}$. Contudo, as mudas que apresentaram período mais curto para transplantio no campo foram as dos tratamentos $\mathrm{T}_{3}$ e $\mathrm{T}_{4}$ (Tabela 1 ).

Este comportamento das mudas pode ser explicado pelo fato do calcário ser um corretivo pouco solúvel, não agindo de imediato no solo, por isso sua aplicação, no estado do Pará, deve ser feita, pelo menos 20 a 30 dias antes do plantio, para que possa reagir e proporcionar o efeito desejado (CRAVO; VIÉGAS; BRASIL, 2010).

Nascimento et al (2007), trabalhando com doses de calcário, não verificaram diferenças na produção matéria seca, em função dos tratamentos aplicados. Observou-se que a altura de plantas e a produção de matéria seca da parte aérea do maracujazeiro foram influenciadas, de forma quadrática, pela aplicação de fósforo e de calcário ao solo. 
Tabela 1. Média de Altura de Plantas (AP), Diâmetro do Caule (DC), Número de Folhas (NF) 61 dias após a germinação.

\begin{tabular}{lccc}
\hline Tratamentos & AP $(\mathrm{cm})$ & DC $(\mathrm{mm})$ & NF \\
\hline T1-Testemunha & $5,06 \mathrm{~b}$ & $1,01 \mathrm{~b}$ & $3,13 \mathrm{~b}$ \\
T2 & $12,65 \mathrm{a}$ & $2,35 \mathrm{a}$ & $6,72 \mathrm{a}$ \\
T3 & $14,27 \mathrm{a}$ & $2,25 \mathrm{a}$ & $7,24 \mathrm{a}$ \\
T4 & $13,86 \mathrm{a}$ & $2,25 \mathrm{a}$ & $7,27 \mathrm{a}$ \\
T5 & $12,00 \mathrm{a}$ & $2,15 \mathrm{a}$ & $6,75 \mathrm{a}$ \\
\hline $\mathrm{CV}(\%)$ & 7,10 & 4,52 & 13,32 \\
\hline
\end{tabular}

As médias seguidas pela mesma letra não diferem estatisticamente entre si. Foi aplicado o Teste de Tukey ao nível de 5\% de probabilidade.

Observou-se que a massa seca da parte aérea foi influenciada significativamente pela interação de níveis de saturação por base e de doses de fósforo. Independente do nível de saturação por bases, a massa da matéria seca da parte aérea das plantas apresentou comportamento semelhante em resposta à aplicação de doses crescentes de fósforo.

Verificou-se um aumento quadrático da matéria seca com o aumento das doses de $\mathrm{P}$, em todas as saturações por bases.

A produção de matéria seca da parte aérea do maracujazeiro em resposta a aplicação de fósforo, associada ao nível de $15 \%$, apresentou tendência ligeiramente inferior aos demais níveis de saturação por bases, que por sua vez apresentaram resultados muito semelhantes, indicando que o nível ótimo de saturação por base encontra-se entre $40 \%$ e $90 \%$.

Com relação à produção de matéria seca da parte aérea e da raiz, observou-se que os máximos incrementos foram alcançados com aplicações de aproximadamente $200 \mathrm{mgdm}^{-3}$ de $\mathrm{P}$, independentemente da saturação por base do solo, indicando a exigência do nutriente pelo maracujazeiro, em condições de baixa disponibilidade no solo.

Observou-se, ainda que, a utilização de calcário potencializou a resposta do maracujazeiro à aplicação de fertilizante fosfatado, verificando-se produção similar, quando as saturações por base estiveram associadas a $40 \%, 65 \%$ e $90 \%$. Ainda segundo Nascimento et al (2007), considerando-se a similaridade dos resultados da produção de matéria seca da parte aérea e da raiz do maracujazeiro, em relação aos níveis de saturação por bases, pode-se supor que o nível equivalente a $40 \%$ seria a melhor opção do ponto de vista econômico, permitindo obter a estimativa de produção ótima de matéria seca da parte aérea $(90 \%$ da 
máxima produção) com a aplicação de $\mathrm{P}$ na dose de $195 \mathrm{mg} \mathrm{dm}^{-3}$, respectivamente.

\section{AVALIAÇÃO DA COMPOSIÇÃO} QUÍMICA DA MATÉRIA SECA DA PARTE AÉREA E RADICULAR DAS MUDAS

Verificou-se que os macronutrientes mais absorvidos foram o nitrogênio e potássio (Tabela 2), conforme afirmam Borges et al. (2003).

As mudas dos tratamentos com adição de calcário absorveram em maior quantidade de nutrientes, como exceção do
$\mathrm{N}$ na parte aérea e do $\mathrm{K}$, Ca e $\mathrm{S}$ na raiz das mudas do tratamento $T_{1}$. Segundo Corrêa et al. (2010 apud OLIVEIRA, 2011), nem sempre a maior concentração de um nutriente significa que o vegetal irá desenvolver-se, a dosagem de nutrientes absorvida pela cultura deve estar de forma equilibrada para que possa alcançar um bom desempenho, sendo importante mencionar que tanto o déficit quanto o excesso de nutrientes (trofobiose) pode acarretar desordens no crescimento das plantas e acabar por prejudicar o seu desenvolvimento.

Tabela 2. Resultados de análises de macronutrientes na parte aérea das mudas do maracujazeiro em casa de vegetação.

\begin{tabular}{|c|c|c|c|c|c|c|}
\hline TRATAMENTOS & $\mathrm{N}$ & $\mathrm{P}$ & $\bar{K}$ & $\mathrm{Ca}$ & $\mathrm{Mg}$ & $\mathrm{S}$ \\
\hline & & & $g$ & $1-\cdots$ & 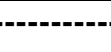 & $\cdots$ \\
\hline Tratamento 1- Folha & 30,45 & 2,20 & 20,00 & 5,68 & 3,19 & 3,25 \\
\hline Raiz & 12,60 & 1,38 & 28,13 & 6,87 & 2,19 & 5,75 \\
\hline Tratamento 2- Folha & 29,05 & 3,95 & 25,62 & 15,61 & 3,44 & 4,53 \\
\hline Raiz & 19,25 & 4,97 & 20,00 & 4,75 & 3,13 & 4,17 \\
\hline Tratamento 3- Folha & 25,55 & 3,58 & 26,25 & 17,05 & 3,75 & 3,43 \\
\hline Raiz & 15,82 & 5,19 & 22,50 & 4,31 & 2,81 & 3,58 \\
\hline Tratamento 4- Folha & 29,12 & 3,95 & 23,75 & 15,11 & 4,06 & 3,61 \\
\hline Raiz & 15,61 & 5,19 & 16,88 & 3,62 & 2,31 & 3,01 \\
\hline Tratamento 5- Folha & 24,29 & 4,76 & 27,50 & 18,17 & 3,44 & 3,43 \\
\hline Raiz & 11,55 & 4,76 & 16,88 & 2,56 & 1,63 & 2,11 \\
\hline
\end{tabular}

Com relação aos micronutrientes (Tabela 3), os mais extraídos pelas plantas de maracujazeiro foram o ferro e o manganês. Verificou-se que as mudas do $\mathrm{T}_{1}$ apresentaram maior absorção para todos os micronutrientes, tanto na parte aérea quanto na radicular, tendo com exceção as mudas do $\mathrm{T}_{3}$ que apresentaram maior assimilação de Cobre em sua parte radicular. 
A redução da disponibilidade de micronutrientes após a calagem, exceto $\mathrm{Cl}$ e Mo, é um fato de ocorrência generalizada (MALAVOLTA, 1980). Dessa maneira, o baixo $\mathrm{pH}$ do solo contribui com a maior disponibilidade dos micronutrientes e consequente absorção pela planta que tende a ser reduzida, a partir do emprego de métodos de correção de acidez do solo (MALAVOLTA et al., 1989).

Tabela 3. Resultados de análises de micronutrientes na parte aérea das mudas do na parte aérea das mudas do maracujazeiro em casa de vegetação.

\begin{tabular}{|c|c|c|c|c|c|}
\hline TRATAMENTOS & $\mathbf{F e}$ & $\mathbf{Z n}$ & $\mathbf{C u}$ & Mn & B \\
\hline & & $\cdots$ & $-1--$ & 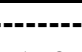 & ---- \\
\hline Tratamento 1- Folha & 488 & 55 & 8 & 163 & 96 \\
\hline Raiz & 3.010 & 75 & 30 & 168 & 600 \\
\hline Tratamento 2- Folha & 255 & 24 & 7 & 60 & 63 \\
\hline Raiz & 2.669 & 46 & 33 & 127 & 282 \\
\hline Tratamento 3- Folha & 287 & 24 & 6 & 56 & 65 \\
\hline Raiz & 1.946 & 46 & 40 & 94 & 521 \\
\hline Tratamento 4- Folha & 331 & 27 & 7 & 80 & 53 \\
\hline Raiz & 2.408 & 47 & 31 & 102 & 521 \\
\hline Tratamento 5- Folha & 283 & 20 & 7 & 57 & 58 \\
\hline Raiz & 1.324 & 22 & 16 & 44 & 584 \\
\hline
\end{tabular}

\section{CONCLUSÃO}

O acréscimo progressivo de calcário dolomítico na produção das mudas de maracujá não se traduziu em crescimento direto das mudas, pois não diferiram entre si, porém em relação às mudas da testemunha o crescimento foi considerado expressivo.

As mudas que apresentaram período mais curto para transplantio no campo foram as dos tratamentos $\mathrm{T}_{3}$ e $\mathrm{T}_{4}$.

Os macronutrientes foram absorvidos pelas mudas em sua maioria pelos tratamentos com adição de calcário dolomítico, já os micronutrientes foram assimilados em sua maioria pelas mudas do tratamento $\mathrm{T}_{1}$.

\section{REFERÊNCIAS}

AGRIANUAL. 2000: Anuário da agricultura brasileira. Maracujá. São Paulo: FNP Consultoria e Comércio, 1999. p.391-406.

ARAÚJO NETO, S. E.; RAMOS, J. D.; MENDONÇA, V.; GONTIJO, R. C. A.; PIO, R.; MARTINS, P. C. C. Desenvolvimento de mudas de maracujazeiro amarelo em diferentes substratos e recipientes. In: CONGRESSO BRASILEIRO DE FRUTICULTURA, 
2002, Belém. Anais... Belém: SBF, 2002. CD-ROM.

BORGES, A. L.; RODRIGUES, M. G. V.; LIMA, A. de A.; ALMEIDA, I. E. de; CALDAS, R. C. Produtividade e qualidade de maracujá-amarelo irrigado, adubado com nitrogênio e potássio. Revista Brasileira de Fruticultura, Jaboticabal SP, v. 25, n. 2, p. 259-262, 2003.

CRAVO, M da. S.; VIÉGAS, I de. J. M.; BRASIL, E. C. Recomendações de Adubação e Calagem para o Estado do Pará. 1. ed. rev. atual. Belém - PA. Embrapa Amazônia Oriental, 2010. 262 p.

DAVI, M. A.; MENDONÇA, V.; REIS, L. L. dos; SILVA, E. A. da; TOSTA, M. da S.; FREIRE, P. de A. Efeito de doses de superfosfato simples e de matéria orgânica sobre o crescimento de mudas de maracujazeiro amarelo. Pesquisa Agropecuária Tropical, v. 38, n. 3, p. 147-152, 2008.

FELDBERG, N. P.; MENDONÇA, V.; RUFINI, J. C. M.; PIO,R.; RAMOS, P. de S.; RAMOS, J. D.; FERREIRA, E. A. Diferentes substratos e ambientes na formação de mudas de maracujazeiro amarelo. In: CONGRESSO BRASILEIRO DE FRUTICULTURA, 18., Florianópolis. Anais...Florianópolis: SBF, 2004. CDROM.

FONSECA, E. B. A. Crescimento do maracujazeiro doce (Passiflora alata Dryand.) em função da calagem, classes de solo e tipo de muda. Tese (Doutorado). Universidade Federalde Lavras, Lavras, 2002.

HAAG, H. P.; OLIVEIRA, G. D.; BORDUCCHI, A. S.; SARRUGE, J. R. Ab-sorção de nutrientes por duas variedades de maracujá. Anais da ESALQ, Piracicaba, v. 30, p. 267-279, 1973.

HOHNE, F. C. Frutas indígenas. São Paulo: Instituto de Botânica, 1946.

LIMA, A.A. A cultura do maracujá. Cruz das Almas: Embrapa Mandioca e Fruticultura, 1999.107p. (Coleção plantar, 41).

MALAVOLTA, E. Elementos de nutrição mineral de plantas. São Paulo: Agronômica Ceres, 1980. 252 p.

MALAVOLTA, E.; VITTI, G. C.; OLIVEIRA, S. A. Avaliação do estado nutricional das plantas: princípios e aplicações. Piracicaba: Associação Brasileira para Pesquisa da Potassa e do Fosfato, 1989. $201 \mathrm{p}$.

MARSCHNER, H. Mineral nutrition of higher plants. London: Academic Press, 1995. 674p.

MACHADO, R. A. F. Fósforo e zinco na nutrição e crescimento de mudas de maracujazeiro amarelo (Passiflora edulis Sins f. flavicarpa Deg). Dissertação (Mestrado). Universidade Federal de Lavras, Lavras, 1998. 
MÜLlER, C. H.; PINHEIRO, R. V. R.; CASALI, V. W. D.; OLIVEIRA, L. M. de; MANICA, I.; SOUZA, C. G. de. Efeito de doses de sulfato de amônio e de cloreto de potássio sobre a produtividade e sobre a qualidade de maracujás colhidos em épocas diferentes. Revista Ceres, Viçosa, v. 26, n. 143, p. 48-64, jan./fev. 1979.

NASCIMENTO, E.V.S.; BRASIL, E.C.; SILVA, F.L. Efeito da aplicação de calcário e de fósforo sobre o crescimento e produção de matéria seca de maracujazeiro amarelo (Passiflora edulis, vr flevicarpa). In: CONGRESSO BRASILEIRO DE CIÊNCIAS DO SOLO, 31., 2007. Anais... Conquistas e desafios da Ciência do Solo. 2007. Gramado - RS.

NOVAIS, R.F.; SMYTH, T.J. Fósforo em solo e planta em condições tropicais. Viçosa: Universidade Federal de Viçosa, 1999. 399p.

OLIVEIRA, I. S. de. Desempenho de mudas de maracujazeiro submetidas a diferentes fertilizantes. 2011. $64 \mathrm{f}$. Trabalho de Conclusão de Curso (Agronomia) - Faculdade de Ciências Agrárias de Marabá, Universidade Federal do Pará, Marabá, 2011.

OLIVEIRA, J. C.; NAKAMURA, K.; MAURO, A. O.; CENTURION, M. A. P. da C. Aspectos gerais do melhoramento do maracujazeiro. In: SÃO JOSÉ, A. R. (Ed.). Maracujá: produção e mercado. Vitória da Conquista: DFZ; UESB, 1994. p. 27-37.
PEREIRA, A. L. C.; CAMPACCI, C. A.; CIANCIULLI, P. L. Maracujá: seu cultivo, espécies e moléstias. In: CONGRESSO BRASILEIRO DE FRUTICULTURA, 1971, Campinas. Anais... Campinas: SBF, 1971. p. 641-658.

PIZA JÚNIOR, C.T.; GUAGGIO, J.A.; SILVA, J.R.; KAVATI, R.; MELETTI, L.M.M.; SÃO JOSÉ, A.R. Adubação do maracujá. In: RAIJ, B. Van.; CANTARELLA, H.; GUAGGIO, J.A.; FURLNI, A.M.C. Recomendações de calagem e adubação para o Estado de São Paulo. Campinas: Instituto Agronômico, 1996. p.148-149.

PRADO, R. M. de; VALE, D. W. do.; ROMUALDO, L. M. Fósforo na nutrição e produção de mudas de maracujazeiro. A cta Sci. Agron. Maringá, v. 27, n. 3, p. 493-498, 2005.

PRADO, R. M. de; NATALE, W.; CORRÊA, M. C. M. de; BRAGHIROLLI, L. F.; Efeito da aplicação de calcário no desenvolvimento, no estado nutricional e na produção de matéria seca de mudas de maracujazeiro. Revista Brasileira de

Fruticultura. V. 26, n. 1, abr. 2004. RAMOS, J. D.; CHALFUN, N. N. J.; PASQUAL, M.; RUFINI, J. C. M. Produção de mudas de plantas frutíferas por semente. Informe Agropecuário, Belo Horizonte, v. 23, n. 216, p. 64-72, 2002. SANTOS, H. G. dos; JACOMINE, P. K. T.; ANJOS, L. H. C. dos; OLIVEIRA, V. 
A. de; OLIVEIRA, J. B. de; COELHO, M. R.; LUMBRERAS, J. F.; CUNHA, T. J. F. Sistema Brasileiro de Classificação de

Solos. 2. ed. Rio de Janeiro: Embrapa Solos, 2006. 306 p.

SÃO JOSÉ, A. R.; SOUZA， I. V.; DUARTE FILHO, J.; LEITE, M. J. Formação de mudas de maracujazeiro. In: SÃO JOSÉ, A. R. (Ed.). Maracujá: produção e mercado. Vitória da Conquista: UESB, 1994. p. 41-48.

SILVA, F. de A. dos S. Programa estatístico ASSISTAT versão 7.5 (Beta). Campina Grande, Paraíba, 2008.

SOUZA, H. A.; GURGEL, R. L. S.; MENDONÇA, V.; RAMOS, P. S.; RAMOS, J. D. Diferentes ambientes e substratos na formação de mudas de mamoeiro formosa. In: CONGRESSO

DE INICIAÇÃO CIENTÍFICA DA UFLA (CICESAL), 2004, Lavras. Anais... Lavras: UFLA, 2004. CD-ROM.

VERDIAL, M. F.; LIMA, M. S. de; TESSARIOLI NETO, J.; DIAS, C. T. dos S.; BARBANO, M. T. Métodos de formação de mudas de maracujazeiro amarelo. Scientia Agricola, Campinas SP, v.57, n.4, p. 795-798, 2000. 